\title{
RESPONS PETANI TERHADAP EFEKTIVITAS PEMBERIAN PUPUK HAYATI PETROBIO TERHADAP PERTUMBUHAN VEGETATIF TANAMAN KACANG TANAH (Arachis hypogaea L.)
}

\section{The Response of Farmer To The Effectiveness of Petrobio Biofertilizer Application On The Vegetative Growth of Peanut (Arachis hypogaea L.)}

\author{
Atika, Syaifuddin, dan Kaharuddin \\ Politeknik Pembangunan Pertanian (Polbangtan) Gowa \\ e-mail: atikahafid101@gmail.com
}

Received: 12 Agustus 2020; Accepted: 22 September 2020; Published: 25 Desember 2020

\begin{abstract}
ABSTRAK
Produktivitas kacang tanah di Indonesia masih sangat rendah, hanya sekitar 1 ton/ha polong kering, sedangkan kebutuhan ke depan diperkirakan terus meningkat, seiring dengan meningkatnya jumlah penduduk. Penelitian bertujuan untuk mengetahui bagaimana efektivitas pemberian pupuk hayati petrobio terhadap pertumbuhan vegetatif tanaman kacang tanah. Penelitian ini dilaksanakan di Kelurahan Samata, Kecamatan Somba Opu, Kabupaten Gowa. Penelitian ini diawali dengan kajian teknis disusun berdasarkan Rancangan Acak Kelompok (RAK) terdiri dari 4 perlakuan, yaitu P0 (tanpa perlakuan), P1 (10 g/tanaman), P2 (20 g/tanaman) dan P3 (30 $\mathrm{g} /$ tanaman), dan masing-masing perlakuan diulang sebanyak 3 (tiga) kali. Parameter pengamatan meliputi tinggi tanaman dan jumlah cabang primer. Kemudian dilanjutkan dengan evaluasi penyuluhan untuk melihat respons petani (perubahan tingkat pengetahuan, sikap, dan keterampilan) terhadap hasil kajian teknis. Hasil penelitian menunjukkan bahwa pemberian beberapa dosis pupuk hayati petrobio terhadap pertumbuhan vegetatif tanaman kacang tanah memberikan pengaruh yang tidak nyata. Pupuk hayati petrobio dengan dosis $10 \mathrm{~g} /$ tanaman memberikan hasil yang tertinggi, yaitu umur 2 MST $(14.20 \mathrm{~cm}), 4$ MST $(21.33 \mathrm{~cm}), 6 \mathrm{MST}$ $(44.87 \mathrm{~cm}), 8 \mathrm{MST}(60.40 \mathrm{~cm})$, sedangkan pada jumlah cabang primer, dosis $30 \mathrm{~g} /$ tanaman memberikan hasil yang tertinggi, yaitu: umur 2 MST (17.67), 4 MST (18.00), 6 MST (11.33), dan 8 MST (11.67). Hasil evaluasi penyuluhan untuk tingkat pengetahuan meningkat dari 38,5\% menjadi 60,92\%, Sikap dari 46,62\% menjadi $76,5 \%$ dan keterampilan dari 40,42\% menjadi 70,82\%, dengan efektivitas penyuluhan berada pada kategori cukup efektif untuk pengetahuan, dan efektif untuk sikap dan keterampilan.
\end{abstract}

Kata kunci: Respons petani, pupuk hayati petrobio, kacang tanah (Arachis hypogaea L.)

\begin{abstract}
Peanut productivity in Indonesia is very low, only about 1 ton/ha of dry pods, while future demand was estimated to continue to increase along with the increasing population. This study aims to determine the effectiveness of petrobio biofertilizer on the vegetative growth of peanut. This research was conducted in Samata Village, Somba Opu District, Gowa Regency. This research begins with a technical experiment was arranged according to randomized block design (RBD) consisting of 4 treatments, i.e.: P0 (without treatment), P1 (10 g/plant), P2 (20 g/plant) and P3 (30 g/plant), and each treatment was repeated 3 (three) times. Observation parameters include plant height and number of primary branches. Then proceed with an evaluation of the extension to see the responses of farmers (changes in the level of knowledge, attitudes, and skills) to the results of technical experiment. The results of research showed that the application of several petrobio biofertilizer dosage on the vegetative growth of peanut have no significant effect. Petrobio biofertilizer at of $10 \mathrm{~g} /$ plant dosage have the highest yield, i.e.: 2 WAP $(14.20 \mathrm{~cm}), 4$ WAP $(21.33 \mathrm{~cm}), 6$ WAP $(44.87 \mathrm{~cm})$,
\end{abstract}

Diterbitkan Oleh,

Unit Penelitian dan Pengabdian Masyarakat, Politeknik Pembangunan Pertanian Gowa

http://ejournal.polbangtan-gowa.ac.id 
8 WAP $(60.40 \mathrm{~cm})$, while for the number of primary branches, $30 \mathrm{~g} /$ plant dosage have the highest results, i.e.: 2 WAP (17.67), 4 WAP (18.00), 6 WAP (11.33), and 8 WAP (11.67). The results of extension evaluation for the level of knowledge increased from $38.5 \%$ to $60.92 \%$, attitudes from $46.62 \%$ to $76.50 \%$ and skills from $40.42 \%$ to $70.82 \%$, with the effectiveness of extension was categorized as effective enough for knowledge, and effective for attitudes and skills.

\section{Keywords: Farmer's response, petrobio biofertilizer, peanuts (Arachis hypogaea L.)}

\section{PENDAHULUAN}

Tanaman kacang tanah (Arachis hypogaea L.) memiliki peran strategis dalam pangan nasional sebagai sumber protein dan minyak nabati. Menurut Arief (2002) dan Sibarani (2005), konsumsi kacang tanah akan terus meningkat sebagai sumber pangan nasional. Pitojo (2005) menguraikan bahwa kebutuhan kacang tanah domestik sampai saat ini belum bisa dipenuhi dari produksi dalam negeri, sehingga Indonesia masih memerlukan substitusi impor dari luar negeri. Untuk mengatasi permasalahan tersebut, maka produksi kacang tanah nasional harus ditingkatkan dalam rangka mencukupi kebutuhan kacang tanah tersebut. Sampai saat ini pemerintah terus berupaya meningkatkan jumlah produksi kecang tanah melalui program intensifikasi, ektensifikasi, dan peningkatan produktivitas tanaman.

Dilihat dari segi produktivitasnya, kacang tanah di Indonesia dinilai masih sangat rendah, hanya sekitar 1 ton/ha polong kering, jauh lebih rendah dibandingkan dengan produktivitas kacang tanah di USA, Cina dan Argentina yang sudah mencapai lebih dari 2 ton/ha. Padahal pada tahun mendatang diperkirakan kebutuhan kacang tanah akan terus meningkat, sejalan dengan meningkatnya jumlah penduduk, kebutuhan gizi masyarakat, dan diversifikasi pangan (Adisarwanto, 2000).

Salah satu cara untuk meningkatkan produktivitas kacang tanah adalah melalui pemupukan, baik dalam bentuk pupuk kimia maupun pupuk organik. konsep pemupukan berimbang sesuai dengan kebutuhan tanaman merupakan salah satu solusi untuk meningkatkan produktivitas tanaman. Pupuk yang digunakan dapat berasal dari pupuk organik maupun anorganik, dan untuk meningkatkan ketersediaan bahan organik dalam tanah, maka digunakan pupuk hayati.
Pupuk hayati ialah bahan yang mengandung mikroorganisme hidup dari mikrobia yang digunakan untuk meningkatkan jumlah mikrobia sehingga dapat menambah ketersediaan unsur hara bagi tanaman (Sugito et al, 1995 dalam Wahyuni, et al, 2009). Pupuk hayati sangat efektif dalam penyediaan nutrisi dan perbaikan sifat tanah dalam mendukung pertumbuhan tanaman. Handayanto (1998) menyatakan bahwa pemanfaatan pupuk hayati yang dikombinasikan dengan pupuk anorganik memberikan prospek yang cukup baik dalam peningkatan produktivitas tanah.

Pupuk Hayati Petrobio merupakan pupuk yang berbentuk padat tetapi mudah larut di tanah jika terkena air dan membawa unsur-unsur hara penting yang dapat meningkatkan kesuburan tanah. Penelitian ini bertujuan untuk: 1) mengetahui efektivitas pemberian berbagai dosis pupuk hayati petrobio terhadap pertumbuhan vegetatif tanaman kacang tanah. 2) mengetahui respons petani terhadap aplikasi berbagai dosis pupuk hayati petrobio terhadap pertumbuhan vegetatif tanaman kacang tanah.

\section{MATERI DAN METODE}

\section{Tempat dan Waktu}

Kajian teknis dan penyuluhan dilaksanakan di lokasi kelompoktani Tamalatea Kelurahan Samata, Kecamatan Somba Opu, Kabupaten Gowa, Provinsi Sulawesi Selatan. Penelitian dilaksanakan mulai dari Maret sampai dengan Mei 2018.

\section{Bahan dan Alat}

Bahan yang digunakan terdiri dari benih kacang tanah, pupuk hayati Petrobio, pestisida nabati dan Pupuk kandang. Alat yang digunakan terdiri dari cangkul, timbangan, meteran, selang air, alat tulis menulis, alat dokumentasi. 


\section{Metode Pelaksanaan}

\section{Kajian teknis}

Kajian teknis dilaksanakan menggunakan Rancanagn Acak Kelompok (RAK), dengan empat perlakuan dan tiga ulangan, yaitu: $\mathrm{P} 0=$ tanpa perlakuan/kontrol, $\mathrm{P} 1=$ dosis $10 \mathrm{~g} /$ tanaman $(360$ g/plot), P2 = dosis $20 \mathrm{~g} / \operatorname{tanaman}(720 \mathrm{~g} / \mathrm{plot})$, dan P3: dosis $30 \mathrm{~g} / \operatorname{tanaman}(1.080 \mathrm{~g} / \mathrm{plot})$.

Sebelum pembuatan bedengan/plot, lahan dibersihkan dari sisa-sisa tanaman sebelumnya, kemudian diolah menggunakan cangkul dengan kedalaman 15-20 cm. Bedengan/plot dibuat dengan ukuran lebar $120 \mathrm{~cm}$, panjang $250 \mathrm{~cm}$, dan tinggi $20 \mathrm{~cm}$. Pada pinggir bedengan dibuat saluran drainase dengan lebar saluran $50 \mathrm{~cm}$, dan kedalaman $30 \mathrm{~cm}$.

Benih kacang tanah yang telah disiapkan adalah benih yang bersertifikat. Benih ditanam pada petakan dengan jarak tanam $20 \times 30 \mathrm{~cm}$ sebanyak 2 biji per lubang. Pemeliharaan tanaman dilakukan, yaitu penyiraman pada pagi dan sore hari, pembersihan gulma, sedangkan untuk pengendalian hama dan penyakit dilakukan dengan menggunakan pestisida nabati.

Parameter pengamatan meliputi: 1) Tinggi tanaman, diukur dari pangkal akar sebagai batas bawah sampai ujung titik tumbuh yang dilakukan setiap 2 minggu sekali dimulai dari tanaman berumur 2 minggu setelah tanam (MST) sampai tanaman berumur 8 MST. 2) Jumlah cabang primer dihitung dari cabang yang keluar dari batang utama, dilakukan bersamaan dengan pengukuran tinggi tanaman.

\section{Evaluasi penyuluhan}

Evaluasi penyuluhan dilakukan untuk mengetahui seberapa besar perubahan pengetahuan, sikap dan keterampilan petani setelah mengikuti kegiatan penyuluhan. Evaluasi penyuluhan dilakukan sebanyak dua kali yaitu evaluasi awal dan evaluasi akhir. Evaluasi awal dilakukan terhadap 25 orang petani responden pada saat awal kegiatan dengan metode pendekatan perorangan berupa kunjungan ke rumah petani, sementara evaluasi akhir dilakukan setelah kegiatan penyuluhan dengan metode pendekatan kelompok.

\section{Teknik Pengumpulan Data}

Pengumpulan data pada kajian teknis dilakukan melalui pengamatan langsung pada setiap parameter pengamatan mulai pada saat tanaman berumur 2 MST sampai 8 MST, sedangkan pada evaluasi penyuluhan, data diperoleh melalui instrumen berupa kuesioner yang diberikan pada saat evaluasi awal dan evaluasi akhir.

\section{Analisis Data}

Data hasil kajian teknis dianalisis dengan menggunakan analisis sidik ragam (anova), dan dilanjutkan dengan Uji Beda Nyata Terkecil, jika ada perbedaan pada setiap parameter pengamatan. Data hasil evaluasi penyuluhan dianalisis melalui perbandingan relatif total skor yang diperoleh terhadap total skor tertinggi untuk semua pertanyaan pada kuesioner pada masing-masing aspek pengetahuan, sikap dan keterampilan. Sedangkan untuk mengetahui efektivitas penyuluhan dihitung dengan menggunakan rumus (Ginting, 1991):

$$
\mathrm{EP}=\frac{\mathrm{Ps}-\mathrm{Pr}}{\mathrm{N} 4 \mathrm{Q}-\mathrm{Pr}} \times 100 \%
$$

Keterangan: Ps $=$ Post test, $\mathrm{Pr}=$ Pree test, $\mathrm{N}=$ Jumlah responden, $4=$ Nilai tertinggi, $Q=$ Jumlah pertanyaan. Nilai persentase efektivitas penyuluhan adalah; $<32 \%=$ kurang efektif, 32-64\%= cukup efektif, dan $>64 \%=$ efektif.

\section{HASIL DAN PEMBAHASAN}

\section{Pertumbuhan Vegetatif Tanaman Kacang Tanah (Arachis hypogaea L.)}

\section{Tinggi tanaman}

Hasil pengukuran rata-rata tinggi tanaman dan pola pertumbuhan tinggi tanaman pada 2 sampai 8 MST disajikan pada Tabel 1 dan Gambar 1, yang memperlihatkan bahwa perlakuan P1 memberikan hasil yang tertinggi dan disusul oleh P3 pada setiap waktu pengamatan. Berdasarkan Tabel 1 dan Gambar 1 dapat dilihat bahwa pertumbuhan tanaman pada umumnya seragam, dimana dengan bertambahnya umur tanaman, tinggi tanaman juga meningkat dan membentuk pola hubungan yang linier.

Diterbitkan Oleh, 
Tabel 1. Rata-rata tinggi tanaman kacang tanah pada pada umur 2 sampai 8 MST

\begin{tabular}{ccccc}
\hline \multirow{2}{*}{ Perlakuan } & \multicolumn{4}{c}{ Umur kacang tanah (MST) } \\
\cline { 2 - 5 } & 2 & 4 & 6 & 8 \\
\hline P0 & 13.84 & 20.20 & 46.67 & 55.00 \\
P1 & 14.20 & 21.33 & 44.87 & 60.40 \\
P2 & 13.53 & 20.87 & 43.87 & 53.80 \\
P3 & 13.97 & 21.03 & 44.33 & 58.67 \\
\hline
\end{tabular}

Hasil Analisis sidik ragam pertumbuhan tinggi tanaman kacang tanah menunjukkan bahwa perlakuan berbagai dosis pupuk hayati petrobio memberikan pengaruh yang tidak nyata. Adanya pengaruh yang tidak nyata pada petrobio lebih disebabkan karena pada dasarnya petrobio lebih berperan dalam mengefektifkan pupuk kimia terutama N dan P. Hal ini didukung oleh Sugiarto
(2008) menyatakan bahwa petrobio berbahan aktif bakteri penambat $\mathrm{N}$-bebas tanpa bersimbiosis dan mikroba pelarut $\mathrm{P}$, terdiri dari mikroba Aspergillus niger, Penicillium sp, Pantoea sp, Azospirillum sp, dan Streptomyces sp., keberadaan mikrobamikroba tersebut mengefektifkan serapan $\mathrm{N}$ dan $\mathrm{P}$ tanah oleh tanaman.

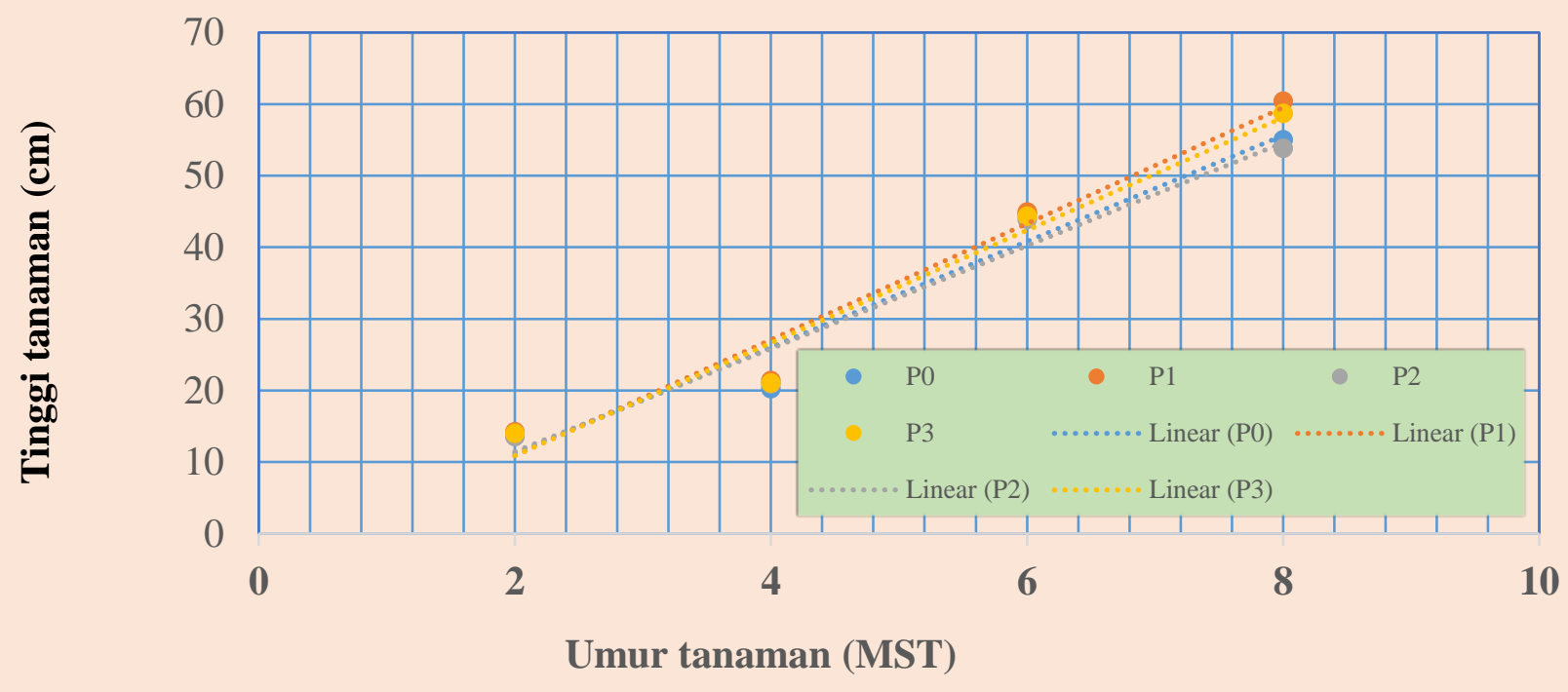

Gambar 1. Pola pertumbuhan tinggi tanaman kacang tanah pada pada umur 2 sampai 8 MST

Bakteri penambat $\mathrm{N}$ dari udara berkemampuan mengikat $\mathrm{N}$ bebas di dalam udara tanah melalui produksi enzim reduktase urea. Bakteri tersebut bersimbiosis dengan akar tanaman dan hidup dalam bintil akar. Simbiosis ini membuat tanaman hanya perlu pasokan sedikit N, Selain itu, mikroba pelarut $\mathrm{P}$ yang digunakan bisa menghasilkan enzim fosfatase, asam-asam organik, dan polisakarida ekstra sel yang membebaskan unsur $\mathrm{P}$ dari senyawa pengikatnya sehingga $\mathrm{P}$ tersedia bagi tanaman (Sugiarto, 2008).

Diterbitkan Oleh, Unit Penelitian dan Pengabdian Masyarakat, Politeknik Pembangunan Pertanian Gowa http://ejournal.polbangtan-gowa.ac.id

\section{Jumlah cabang primer}

Hasil pengukuran rata-rata cabang primer dan pola perkembangan jumlah cabang primer pada 2 sampai 8 MST disajikan pada Tabel 2 dan Gambar 2, yang memperlihatkan bahwa perlakuan P3 memberikan hasil yang tertinggi pada setiap waktu pengamatan. Berdasarkan Tabel 1 dan Gambar 1 dapat dilihat bahwa pertumbuhan tanaman pada umumnya seragam, dimana dengan bertambahnya umur tanaman, jumlah cabang primer yang bertahan hidup menurun dan membentuk pola hubungan yang linier negatif. 
Tabel 2. Rata-rata jumlah cabang primer kacang tanah pada pada umur 2 sampai 8 MST

\begin{tabular}{ccccc}
\hline \multirow{2}{*}{ Perlakuan } & \multicolumn{4}{c}{ Umur kacang tanah (MST) } \\
\cline { 2 - 5 } & 2 & 4 & 6 & 8 \\
\hline P0 & 13.73 & 15.50 & 9.67 & 10.67 \\
P1 & 15.93 & 16.67 & 10.00 & 10.67 \\
P2 & 16.67 & 16.67 & 11.33 & 10.93 \\
P3 & 17.67 & 18.00 & 11.33 & 11.67 \\
\hline
\end{tabular}

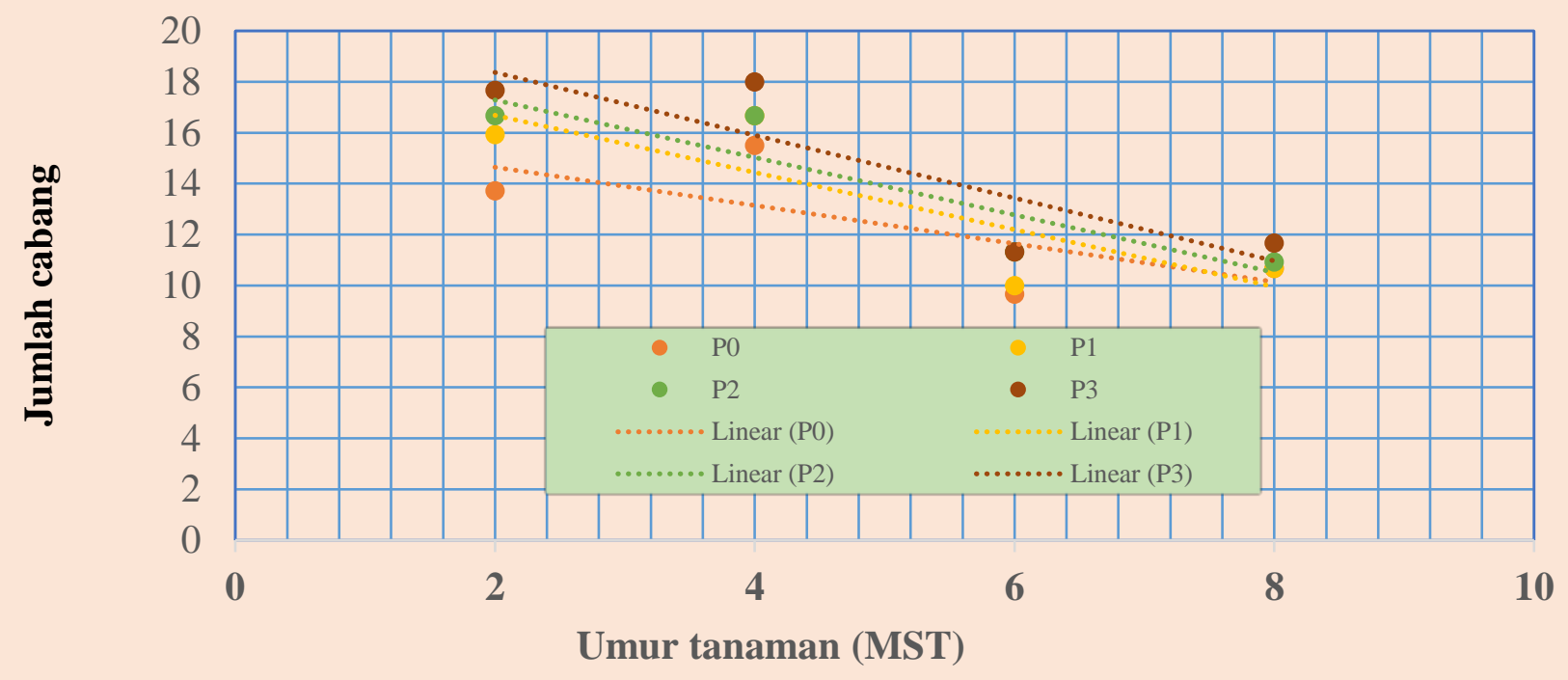

Gambar 2. Pola pertumbuhan jumlah cabang primer kacang tanah pada pada umur 2 sampai 8 MST

Hasil analisis sidik ragam jumlah cabang primer kacang tanah menunjukkan bahwa perlakuan berbagai dosis pupuk hayati petrobio memberikan pengaruh yang tidak nyata. Pengaruh tidak nyata ini, disebabkan karena peranan petrobio yang hanya berfungsi untuk mengefektifkan penggunaan unsur hara oleh tanaman. Jika unsur hara tersedia dalam tanah, khususnya $\mathrm{N}, \mathrm{P}$, dan $\mathrm{K}$ maka tanaman akan berkembang dengan optimal, dimana batang, daun akan berkembang dengan baik, bahkan unsur $\mathrm{P}$ sangat berperan dalam pembentukan bunga dan buah (Soepardi, 1983). Selain pengaruh unsur hara, jumlah cabang primer juga banyak ditentukan oleh sifat varietas kacang tanah yang digunakan melalui proses daya adaptasi terhadap lingkungan (Reiza et. al, 2017).

\section{Evaluasi Penyuluhan Pertanian}

Evaluasi penyuluhan dilakukan untuk mengetahui seberapa besar perubahan pengetahuan, sikap dan keterampilan petani setelah mengikuti kegiatan penyuluhan. Perubahan tingkat pengetahuan dan sikap petani responden secara detail disajikan pada Tabel 3. Tabel 3 menunjukan bahwa tingkat pengetahuan, sikap, dan keterampilan responden mengalami peningkatan. Hal ini menunjukkan bahwa respons petani cukup baik dalam menyikapi suatu inovasi teknologi. Dalam proses penyuluhan, tujuan yang ingin dicapai adalah adanya perubahan pengetahuan, keterampilan, dan sikap (Mardikanto, 1993). Belum tingginya nilai persentase perubahan yang diperoleh menunjukkan bahwa respons dari petani masih berbeda-beda dalam menanggapi suatu inovasi teknologi, sejalan dengan hal ini, Mardikanto (1993) menjelaskan bahwa respons yang berbeda-beda dari petani disebabkan oleh berbagai faktor internal dan eksternal dari petani itu sendiri. Lebih lanjut dijelaskan bahwa dalam proses adopsi juga terdapat beberapa golongan, di

Diterbitkan Oleh, 
antaranya: 1) golongan inovator/perintis, 2) golongan penerap dini, 3) golongan penerap awal, 4) golongan penerap akhir/lambat, 5) golongan penolak/laggard yang sangat sulit dalam merubah cara hidupnya.

Salah satu faktor internal petani yang paling berpengaruh terhadap adopsi teknologi adalah tingkat pendidikan. Tingkat pendidikan mempengaruhi cara berpikir dan cara pandang seseorang dalam menjalankan kegiatan usahataninya (Hernanto, 1984). Nuhung (2003) menguraikan bahwa salah satu parameter rendahnya tingkat pendidikan petani jika kegiatan usahataninya masih dikelola secara tradisional. Salah satu kendala dalam upaya introduksi teknologi inovasi adalah rendahnya kualitas SDM masyarakat pertanian, sehingga diperlukan bimbingan yang intensif. Salikin (2003) menguraikan bahwa pengembangan SDM pertanian sebagai pelaku utama pembangunan pertanian sangat diharapkan dan merupakan investasi masa depan menuju pembangunan pertanian berkelanjutan.

Tabel 3. Peningkatan Pengetahuan, Sikap dan Keterampilan Petani Responden setelah dievaluasi di Kelompoktani Tamalatea

\begin{tabular}{llrrcrcrc}
\hline \multirow{2}{*}{ No } & \multirow{2}{*}{ Deskripsi } & Skor & \multicolumn{3}{c}{ Nilai yang diperoleh } & \multicolumn{3}{c}{ Efektivitas Penyuluhan } \\
\cline { 4 - 8 } & & Maks. & Tes awal & $\%$ & Tes akhir & $\%$ & $\%$ & Kriteria \\
\hline 1 & Pengetahuan & 1.000 & 385 & 38.50 & 692 & 69.20 & 49.91 & C. efektif \\
2 & Sikap & 800 & 373 & 46.62 & 612 & 76.50 & 56.20 & Efektif \\
3 & Keterampilan & 700 & 283 & 40.42 & 496 & 70.82 & 51.07 & efektif \\
\hline
\end{tabular}

\section{KESIMPULAN}

1. Pupuk hayati petrobio dengan dosis 10 $\mathrm{g} /$ tanaman memberikan hasil yang tertinggi pada parameter tinggi tanaman, yaitu: umur 2 MST $(14.20 \mathrm{~cm}), 4$ MST $(21.33 \mathrm{~cm}), 6$ MST $(44.87 \mathrm{~cm})$, dan 8 MST $(60.40 \mathrm{~cm})$, sedangkan pada jumlah cabang primer, dosis 30 g/tanaman memberikan hasil yang tertinggi, yaitu: umur 2 MST (17.67), 4 MST (18.00), 6 MST (11.33), dan 8 MST (11.67).

2. Hasil evaluasi penyuluhan menunjukkan bahwa tingkat pengetahuan meningkat dari $38,5 \%$ menjadi $60,92 \%$, Sikap dari $46,62 \%$ menjadi $76,5 \%$ dan keterampilan dari $40,42 \%$ menjadi 70,82\%, dengan efektivitas penyuluhan, yaitu untuk pengetahuan $49,91 \%$ (cukup efektif), sikap 56.20\% (efektif), dan keterampilan $51.07 \%$ (efektif).

\section{DAFTAR PUSTAKA}

Adisarwanto. T., 2000. Meningkatakan produksi kacang tanah dilahan sawah dan lahan kering. Penebar Swadaya. Malang

Arief, H. 2002. Penelitian paket teknologi budidaya kacang tanah dilahan kering. Dalam: penelitian mendukung peningkatan produksi tanaman pangan, BPTP Malang.

Ginting, E., 1991. Metode Kuliah Kerja Lapang. Universitas Brawijaya Malang.

Handayanto, E., 1998 Pengelolaan kesuburan tanah secara biologi untuk menuju sistem pertanian sustainabel. Habitat 4 (10): 104110.

Hernanto, 1984. Petani Kecil, Potensi dan Tantangan Pembangunan. PT. Ganesia, Jakarta.

Mardikanto, 1993. Penyuluhan Pembangunan Pertanian. UNS Press, Surakarta.

Pitojo, S., 2005. Benih Kacang Tanah. Kanisius, Yogyakarta.

Reiza, M., T. Irmansyah, F.E.T Sitepu. 2017. Pertumbuhan dan produksi dua varietas kacang tanah (Arachis hypogaea L.) terhadap aplikasi pupuk kandang sapi. Jurnal Agroteknologi FP USU 5 (1): 152 159.

Salikin, K.A., 2003. Sistem Pertanian Berkelanjutan. Penerbit Kanisius, Yogyakarta.

Sibarani, F.M.A., 2005. Budidaya Kacang Tanah. Swadaya, Yogyakarta.

Soepardi, G., 1983 Sifat dan Ciri Tanah. Institut Pertanian Bogor, Bogor.

Diterbitkan Oleh,

Unit Penelitian dan Pengabdian Masyarakat, Politeknik Pembangunan Pertanian Gowa

http://ejournal.polbangtan-gowa.ac.id 
Sugiarto, Y., 2008. Petrokimia Gresik luncurkan pupuk hayati. [Diakses 24 Februari 2017 pada situs http://www.agrina-online.com.].

Wahyuni, S.T., T. Islami, H.T. Sebayang, dan B. Hariyono, 2009 Pengaruh pupuk hayati petrobio dan pupuk $\mathrm{N}, \mathrm{P}, \mathrm{K}$ pada pertumbuhan awal tanaman jarak pagar (Jatropa curcas L.). [Diakses 24 Februari 2012 pada situs http://Pustaka pertanian ub.staff.ub.ac.id/files/2012/01/jurnal.pdf]. 